\title{
The Effect of Coordinate System Variation on In Vivo Patellofemoral Kinematic Measures
}

\author{
Angela E. Kedgley, $\mathrm{PhD}^{\mathrm{a}, 1}$ \\ Emily J. McWalter, PhD ${ }^{\mathrm{b}, 2}$ \\ David R Wilson, DPhil ${ }^{\mathrm{a}, \mathrm{c}}$ \\ a Department of Orthopaedics \\ University of British Columbia \\ 3114 - 910 West 10th Avenue \\ Vancouver, BC V5Z 1M9 Canada \\ ${ }^{b}$ Department of Mechanical Engineering \\ University of British Columbia \\ 2054-6250 Applied Science Lane, \\ Vancouver, BC V6T 1Z4 Canada \\ ${ }^{\mathrm{c}}$ Centre for Hip Health and Mobility \\ Vancouver Coastal Health Research Institute \\ 7/F, 2635 Laurel Street \\ Robert H.N. Ho Research Centre \\ Vancouver, BC V5Z 1M9 Canada \\ ${ }^{1}$ Present address: Department of Bioengineering \\ Imperial College London \\ South Kensington Campus \\ London, SW7 2AZ United Kingdom \\ ${ }^{2}$ Present address: Department of Radiology \\ The Lucas Center for MR Spectroscopy and Imaging \\ P064-1201 Welch Road \\ Stanford, CA 94305-5488 United States of America
}

Correspondence:

Angela E. Kedgley

Department of Bioengineering

Imperial College London

South Kensington Campus

London, SW7 2AZ

United Kingdom

Phone: $01144(+0) 2075940747$

Email: akedgley@imperial.ac.uk 


\section{Abstract}

Background: The use of different coordinate system definitions for the patella leads to difficulties in comparing kinematic results between studies. The purpose of this work was to establish the effect of using a range of coordinate system definitions to quantify patellar kinematics. Additionally, intra- and inter-investigator repeatabilities of the digitization of anatomic landmarks on the patella were determined.

Methods: Four different patellar coordinate system definitions were applied using digitisations in two and three dimensions and a single femoral coordinate system was used for comparison. Intra-investigator variability was established by having one investigator digitize the patellar landmarks of three subjects on five separate occasions. Inter-investigator variability was quantified by having five participants digitize the same landmarks on the same three subjects. Patellofemoral kinematics were quantified for ten subjects, at six angles of tibiofemoral flexion, using MRI.

Results: As a result of changes in the patellar coordinate system, differences of up to $11.5^{\circ}$ in flexion, $5.0^{\circ}$ in spin, and $27.3^{\circ}$ in tilt were observed in the resultant rotations for the same motion, illustrating the importance of standardizing the coordinate system definition.

Conclusions: To minimize errors due to variability while still maintaining physiologically sensible kinematic angles, a coordinate system based upon an intermediate flexion axis between the most medial and lateral points on the patella, and a 
superiorly-directed long axis located between the most proximal and distal points on the patella, with an origin at the centre of the most proximal, distal, medial, and lateral points on the patella is recommended.

Keywords: coordinate system; patella; landmarks; patellofemoral kinematics 


\section{Introduction}

Patellar kinematics have been measured in a wide range of studies of normal, pathological and treated knees. An essential step in describing kinematics is defining a coordinate system at the joint, but there is currently no standard definition of a coordinate

5 system for the patella. This makes comparing results across the literature difficult, if not impossible [1]. The most widely used method of assigning coordinate systems is to select anatomical landmarks that allow the creation of an origin point, a flexion axis, and a long axis. A third axis is determined from the cross product of the long and flexion axes, and an orthogonal flexion axis is then found by taking the cross product of this third axis with

10 the long axis. An orthogonal coordinate system is consequently formed by the second flexion axis, the long axis and the third axis. Many combinations of landmarks have been used to assign coordinate systems to the femur and patella (Table 1), and these are likely responsible, in part, for the variability in patellofemoral kinematics that is seen in the literature.

Alternatives to anatomical coordinate system definitions include fitting a bounding box $[22,23]$ and the recently proposed method of an automated algorithm that makes use of the posterior ridge of the patella [20]. Although these two methods will result in repeatable coordinate frame definitions, their automated nature means that they may not always align with patellar anatomy. In particular, the use of a bounding box is

20 affected by the orientation of the knee in the scanner. Obviously, other confounding factors include natural and pathological anatomic variability of the patella and femur $[24,25]$. However, in order to determine the effects of pathologies a consistent means of 
quantifying changes must be established and this requires a consistent way to quantify "normal" anatomy and kinematics.

There have been several attempts to quantify errors in coordinate system creation and to standardize aspects of its application, but no standard definition has been proposed and implemented by the biomechanics community. Bull et al. investigated various methods of describing patellofemoral motion and also compared the kinematic outcomes of using two different femoral flexion and long axis definitions [1]. However, the effect

30 of the variation of the patellar coordinate system was not investigated. Several investigators have quantified the repeatability $[2,12,26-28]$ and sensitivity [11] of the creation of their particular patellar coordinate systems. Katchburian et al. [29] conducted a thorough review of patellar kinematics and recommended the coordinate system described by Lafortune [30] as being the 'most useful', possibly because it follows the

35 method suggested by Grood and Suntay [31]. However, this is the only direct comparison of a range of coordinate systems in the literature to date.

Within the clinical community several studies have examined inter- and intraobserver variability of patellar measures such as sulcus angle, congruence angle, patellar height, patellar axis, lateral patellofemoral angle, lateral patellar tilt [32-34].

40 Unfortunately, these measures do not describe three-dimensional kinematics, and therefore cannot fully characterize patellar motion.

Selection of appropriate landmarks that allow for coordinate system creation is important. Landmarks should be defined without ambiguity and it should be possible to digitize them repeatably. The landmarks for an in vitro study, which may involve 45 disarticulation of the joint, may not be appropriate for an in vivo study. The use of 
palpation in vivo may yield different results to those obtained from an imaging study. Additionally, imaging modalities, such as computed tomography (CT) $[35,36]$ and magnetic resonance imaging (MRI) scans [8,18,19,37-39] are increasingly being employed to measure patellar kinematics. The locations of the required landmarks may

50 be digitized from these scans using two- or three-dimensional imaging techniques. Two dimensional techniques are prone to projection errors due to the alignment of the subject within the imaging device [40], and therefore it would seem that three-dimensional measures would be preferable.

The selection of a preferred coordinate system should provide, at the very least, a 55 repeatable way to quantify kinematics, allowing the same reference frames to be employed for a range of subjects, thereby facilitating comparisons between them. In addition, as mentioned by $\mathrm{Wu}$ et al., clinically relevant kinematic results, which can be used to interpret the movements of the bones in a meaningful way, are preferable [41].

Therefore, in this study the research questions were:

- What are the intra- and inter-investigator repeatabilities of the digitization of anatomic landmarks on the patella from MRI images?

- What are the effects of varying the patellar coordinate system definition on the resulting in vivo three-dimensional patellofemoral kinematics?

- Is there one patellar coordinate system definition that is preferable over all others for use with imaging techniques?

\section{Methods}

\subsection{Subjects and imaging}


Ten normal subjects with no history of knee pain, injury, osteoarthritis, surgery, or contraindication to MRI were recruited to participate in this study (4 female, 6 male, $34 \pm$

706 yrs, $70.8 \pm 15.8 \mathrm{~kg}$ ). Institutional ethics board approval was obtained and each subject provided informed consent. A initial MRI scan was acquired in the sagittal plane with the subject's knee in a relaxed position using a 3T MRI scanner (Intera, Phillips, Best, The Netherlands) and the following parameters: $0.586 \mathrm{~mm}$ in-plane resolution, $300 \mathrm{~mm}$ field of view, $2 \mathrm{~mm}$ slice separation, 512 x 512 matrix size, $360 \mathrm{~ms}$ repetition time, $10.0 \mathrm{~ms}$

75 echo time, $90^{\circ}$ flip angle, knee MRI coil. Subject-specific bone models of the femur and patella were created from this scan [42]. Six additional MRI scans were then acquired in the sagittal plane with the following parameters: $1.25 \mathrm{~mm}$ in-plane resolution, $320 \mathrm{~mm}$ field of view, $7 \mathrm{~mm}$ slice separation, 256 x 256 matrix size, $307 \mathrm{~ms}$ repetition time, $6.2 \mathrm{~ms}$ echo time, $90^{\circ}$ flip angle, body MRI coil. For each scan the subject's knee was placed in

80 one of six flexion angles, ranging from $0^{\circ}$ to $50^{\circ}$, in increments of $10^{\circ}$, with a load of $15 \%$ bodyweight applied to the foot [42]. To determine the joint angles from the loaded scans, the bone models were registered to the images using an Iterative Closest Points algorithm implemented in Matlab (The MathWorks, Natick, MA, USA) [42].

\subsection{Landmark digitization}

Digitization of landmarks from the high-resolution scans was performed using Analyze 8.1 (Analyze Direct Inc, Overland Park, KS, USA) image processing software. The locations of seven landmarks on the bony surface of the patella were digitized and the locations of three additional points were calculated (Table 2, Fig. 1). Landmarks were selected only if they were applicable to an in vivo analysis (i.e. they could be

90 determined through palpation and/or imaging techniques). The insertions of the 
quadriceps and patellar tendons were not included for this reason, although they have been used in the literature. Possible origin locations were selected from among those that were previously used in the literature for being well defined, applicable to an in vivo analysis, and based solely on patellar landmarks.

The position of each digitized landmark was identified by a single point selection.

Intra-investigator variability was established by having one investigator digitize the patellar landmarks of three subjects on five separate occasions. Inter-investigator variability was quantified by having four other participants digitize the same landmarks on the same three subjects. All participants were given the same set of written

100 instructions to follow and were asked to record all intermediate data, such as the calculation of a mid-slice location. The variability of the digitized landmarks and calculated locations was represented by the mean of the three radii defining the smallest ellipsoid that contained all of the points with a tolerance of $1 \times 10^{-6} \mathrm{~mm}$ [43].

\subsection{Coordinate system variation}

To determine how differences in the patellar coordinate system axes affect threedimensional kinematics, four different patellar axis definitions were applied to each subject. The landmarks that were selected as the basis of the flexion and long axes for each coordinate system are listed in Table 3. For each definition the cross product of the long axis and the flexion axis yielded the third, anteriorly-pointing axis. The cross

110 product was again applied to the third axis and the long axis to obtain an orthogonal flexion axis. Positive directions for the right-handed coordinate systems were proximal, lateral, and anterior, respectively. Rotations about the three axes were found using a modified Joint Coordinate System convention $[8,44]$. The origin was the same for all 
patellar coordinate systems and was based upon landmarks chosen according to the

115 repeatability results of the previous section. Each coordinate system was applied to both the two- and three-dimensional digitizations, resulting in a total of eight coordinate system trials.

In order to facilitate the comparison of the patellar coordinate systems, a single femoral coordinate system was created for each subject, with a flexion axis between the

120 most posterior points on the femoral condyles, and the long axis from the centre of the femur at the midshaft to the centre of the shaft above the condyles. Again, two cross products were applied to obtain an orthogonal right-handed coordinate system, the first between the long and flexion axes, and the second between the third and long axes. The origin for the femoral coordinate system was the most proximal point of the intercondylar

\section{5 notch [15].}

\subsection{Landmark and coordinate system comparisons}

The repeatabilities of intra- and inter-investigator digitizations were compared by ranking the means of the three radii defining the smallest ellipsoid that contained all of the selections of a particular landmark [43]. The repeatabilities of potential locations for

130 the patellar coordinate system origin were ranked in a similar way. Variability of the kinematic quantities was defined as the standard deviations of flexion, spin, and tilt over all six knee flexion angles for the three repeatedly measured subjects. To establish the effect of choosing a different coordinate system on the kinematic outcomes the mean absolute differences between resultant rotations were calculated for the full ranges of 135 motion of all ten subjects. In addition, we tested the hypothesis that coordinate system 
definition changed joint kinematics using Wilcoxon signed rank tests and Spearman rank correlation coefficients (SRCCs). Significant differences were defined as $\mathrm{p}<0.05$.

\section{Results}

\subsection{Landmark digitization}

The patellar landmark with the least intra- and inter-investigator variability was the most distal point in both two (Dist-2) and three dimensions (Dist-3; Table 2). In terms of inter-investigator variability only, in three dimensions the second and third least variable landmarks were the most lateral point on the patella (Lat-3) and the most distal point on the patellar spine (Dist.Spine-3). The landmark with the most intra- and inter-

145 investigator variability in three dimensions was the most posterior point on the patella (Post-3). Based upon these results, when digitizations were performed in three dimensions, it would be expected that the first coordinate system definition (3D-1) would be the most repeatable. In two dimensions the second and third least variable landmarks were the most distal (Dist.Spine-2) and most proximal (Prox.Spine-2) points on the 150 patellar spine.

The origin location with the least intra- and inter-investigator variability in three dimensions was the centre of the most proximal, distal, medial, and lateral points (Centre3; Table 2). In two dimensions, the most repeatable point was the midpoint of the most proximal and distal points of the patellar spine (Prox.Dist-2).

\section{$155 \quad 3.2$ Coordinate system variation}

As anticipated from the results of the landmark digitizations, in three dimensions

3D-1 produced the least variable results overall (Fig. 2). In two dimensions 2D-1 and 2D-2 had the least variability in kinematic output. A representative set of coordinate 
systems are shown in Figure 3. The greatest differences in mean kinematic angles were

160 between coordinate systems 3D-2 and 3D-3 with average differences of $11.5^{\circ}$ in flexion, $5.0^{\circ}$ in spin, and $27.3^{\circ}$ in tilt (Table 4); however, statistically significant differences were found between many of the coordinate systems. The only pair with no significant differences between two and three dimensions was 2D-2 and 3D-2. Despite this, SRCCs amongst coordinate systems in two or three dimensions revealed excellent agreement

165 between all coordinate system definitions in flexion in both ( $\mathrm{SRCC} \geq 0.970$ ), as well as in spin and tilt in two dimensions ( $\mathrm{SRCC} \geq 0.881$ and 0.903 respectively). Low agreement was found in spin and tilt in three dimensions ( $\mathrm{SRCC} \geq 0.445$ and $\geq 0.622$ respectively). SRCCs between coordinate systems in two and three dimensions using the same landmarks showed the highest agreement between 2D-1 and 3D-1 $(\mathrm{SRCC}=0.996$ in 170 flexion, 0.792 in spin, and 0.920 in tilt).

\section{Discussion}

We assessed the effects of varying the patellar coordinate system definition on patellofemoral kinematic quantities and the intra- and inter-investigator repeatabilities of the digitization of anatomic landmarks on the patella from MRI images because a

175 standard coordinate system for the patella has yet to be proposed or adopted. Our results show clearly that the choice of anatomic landmarks can result in large changes in the resultant patellar rotations with respect to the femur. It is therefore not surprising that results have varied greatly in the literature, even in studies of healthy individuals [29]. It is likely that even more variation would be observed in pathological joints, where

180 landmarks may not have the same relative positions; this makes it all the more important to standardize the patellar coordinate system in studies of pathological joints.. 
In general, the intra- and inter-investigator repeatabilities of landmark digitization were comparable to previous studies. The average radii of the points selected by five investigators were on the same order as, and generally less than, those found by a similar 185 study that examined landmarks of the scapula [43]. These results are also on the same order as those of Ahmed et al. and Belvedere et al., who quantified the variability of their respective patellar coordinate system definitions in cadaveric specimens [2,12]. As would be expected, intra-observer repeatability was better than inter-observer repeatability, so if possible a single investigator should perform all digitization for a 190 given study.

The choice of coordinate system had a substantial effect on three-dimensional patellar kinematic quantities and their repeatability. The differences in kinematic quantities between coordinate systems were much larger than anticipated, with the greatest differences observed in tilt. The differences were clearly associated with

195 differences in the landmarks used to define their axes. For example, the patellofemoral flexion angle was dictated by the landmarks that were selected to define the long axis, and patellofemoral tilt was affected by flexion axis definition. These correspondences were also found by Morton et al. in their probabilistic analysis examining the sensitivity of patellofemoral kinematics to anatomical landmark locations in a cadaver model [28].

200 The large differences emphasize the importance of standardizing the patellar coordinate system.

The most suitable coordinate system for any given application is generally the one that yields the least variability, and the choice will be dictated by whether the measurements are made in two or three dimensions. For three dimensional 
measurements, 3D-1 is recommended, to minimize confounding errors. To maintain consistency, the use of 2D-1 is similarly recommended when digitizations are to be performed in two dimensions. The differences between the resultant kinematic angles from these two coordinate system definitions in two and three dimensions are small and their agreement is high, as demonstrated by the SRCCs. The origin location should also

210 be the point with the least variability, namely Centre-3 in three dimensions and Centre-23 in two dimensions.

The use of a single digitizing modality may be viewed as a limitation; however, the aim of this study was not to compare software packages, and these results are considered to be representative of what would be expected in an MRI-based study. In

215 addition, the use of mathematical models to determine coordinate systems automatically was not addressed. Due to their automated nature, it is expected that the repeatability would be high; however, as noted previously, in particular when using a bounding box method the alignment of the axes are affected by the alignment of the subject within the scanner. It has been noted that certain joint pathologies may alter the shape of the patella

220 and this might affect the identification of the landmarks described herein. This study examined only healthy participants in order to establish a benchmark of reliability.

Strengths of this study include a thorough quantification of the repeatability of digitizing patellar landmarks in vivo, the production of a framework for comparing data between studies using various patellar coordinate system definitions, and the proposal of 225 a standardized, repeatable patellar coordinate system.

The methods proposed here focused on the definition of the patella coordinate frame itself and how it affects resultant kinematics. The recommended anatomic 
coordinate frame may be employed in the calculation of dynamic in vivo patellar kinematics when used in combination with any method that reliably quantifies patellar

230 motion. For example, MRI may be used to obtain a detailed model of the patella, on which the coordinate axes could be established, and which could then be registered to fluoroscopic images of the patella in motion.

\section{Conclusion}

In conclusion, we recommend a standard patellar coordinate system with an

235 intermediary flexion axis defined between the most medial and lateral points of the patella, a superiorly-directed long axis defined between the most proximal and distal points on the patella, an anteriorly-directed axis that is the result of a cross product of these first two axes, and a final laterally-directed flexion axis that is the result of the cross product of the superior and anterior axes. The origin should lie at the centre of the most

240 proximal, distal, medial, and lateral points. This would minimize kinematic measurement variability caused by landmark selection and allow better comparisons of results reported by differing research groups.

\section{Conflict of interest statement}

There are no commercial or personal relationships with any other persons or

245 organizations that may lead to conflicts of interest.

\section{Acknowledgements}

The authors would like to thank Marianne Black, Agnes d'Entremont, and Kenard Agbanlog who digitized the landmarks for this study, Kelly A. Hirko for aiding in recruiting and data collection, and Kelley Erb and Kevin Hallock for acquiring the MRI

250 scans. The authors would also like to acknowledge funding from Natural Sciences and 
Engineering Research Council (AK, EM), the Canadian Arthritis Network/The Arthritis Society of Canada Training Program (EM), Michael Smith Foundation for Health Research (EM), Canadian Institutes of Health Research (DW) and a Boston University School of Medicine institutional grant (David Hunter). 


\section{References}

[1] Bull AMJ, Katchburian MV, Shih Y-F, Amis AA. Standardisation of the description of patellofemoral motion and comparison between different techniques. Knee Surg Sports Traumatol Arthrosc 2002;10:184-93.

[2] Belvedere C, Catani F, Ensini A, Moctezuma de la Barrera JL, Leardini A. Patellar tracking during total knee arthroplasty: an in vitro feasibility study. Knee Surg Sports Traumatol Arthrosc 2007;15:985-93.

265 [3] Hsu HC, Luo ZP, Rand JA, An KN. Influence of patellar thickness on patellar tracking and patellofemoral contact characteristics after total knee arthroplasty. J Arthroplasty 1996;11:69-80.

[4] Lee TQ, Sandusky MD, Adeli A, McMahon PJ. Effects of simulated vastus medialis strength variation on patellofemoral joint biomechanics in human cadaver knees. $\mathbf{J}$ Rehabil Res Dev 2002;39:429-38.

[5] Powers CM, Lilley JC, Lee TQ. The effects of axial and multi-plane loading of the extensor mechanism on the patellofemoral joint. Clin Biomech 1998;13:616-24.

[6] Sakai N, Luo ZP, Rand JA, An KN. The influence of weakness in the vastus medialis oblique muscle on the patellofemoral joint: an in vitro biomechanical study. Clin Biomech 2000;15:335-9.

280 [7] Amis AA, Senavongse W, Bull AM. Patellofemoral kinematics during knee flexionextension: an in vitro study. J Orthop Res 2006;24:2201-11.

[8] Fellows RA, Hill NA, Gill HS, MacIntyre NJ, Harrison MM, Ellis RE, et al. Magnetic resonance imaging for in vivo assessment of three-dimensional patellar tracking. J Biomech 2005;38:1643-52.

[9] Sheehan FT, Zajac FE, Drace JE. In vivo tracking of the human patella using cine phase contrast magnetic resonance imaging. J Biomech Eng 1999;121:650-6.

290 [10] Kwak SD, Ahmad CS, Gardner TR, Grelsamer RP, Henry JH, Blankevoort L, et al. Hamstrings and iliotibial band forces affect knee kinematics and contact pattern. J Orthop Res 2000;18:101-8.

[11] Shin CS, Carpenter RD, Majumdar S, Ma CB. Three-dimensional in vivo patellofemoral kinematics and contact area of anterior cruciate ligament-deficient and -reconstructed subjects using magnetic resonance imaging. Arthroscopy 2009;25:1214-23.

[12] Ahmed AM, Duncan NA, Tanzer M. In vitro measurement of the tracking pattern of the human patella. J Biomech Eng 1999;121:222-8. 
[13] Hefzy MS, Jackson WT, Saddemi SR, Hsieh YF. Effects of tibial rotations on patellar tracking and patello-femoral contact areas. J Biomed Eng 1992;14:329-43.

305 [14] van Kampen A, Huiskes R. The three-dimensional tracking pattern of the human patella. J Orthop Res 1990;8:372-82.

[15] Lerner AL, Tamez-Pena JG, Houck JR, Yao J, Harmon HL, Salo AD, et al. The use of sequential MR image sets for determining tibiofemoral motion: reliability of

310 coordinate systems and accuracy of motion tracking algorithm. J Biomech Eng 2003; 125:246-53.

[16] Ostermeier S, Holst M, Hurschler C, Windhagen H, Stukenborg-Colsman C. Dynamic measurement of patellofemoral kinematics and contact pressure after 315 lateral retinacular release: an in vitro study. Knee Surg Sports Traumatol Arthrosc 2007; 15:547-54.

[17] Mizuno Y, Kumagai M, Mattessich SM, Elias JJ, Ramrattan N, Cosgarea AJ, et al. Q-angle influences tibiofemoral and patellofemoral kinematics. J Orthop Res $320 \quad 2001 ; 19: 834-40$.

[18] Sheehan FT, Zajac FE, Drace JE. Using cine phase contrast magnetic resonance imaging to non-invasively study in vivo knee dynamics. J Biomech 1998;31:21-6.

325 [19] Seisler AR, Sheehan FT. Normative three-dimensional patellofemoral and tibiofemoral kinematics: a dynamic, in vivo study. IEEE Trans Biomed Eng 2007;54:1333-41.

[20] Rainbow MJ, Miranda DL, Cheung RT, Schwartz JB, Crisco JJ, Davis IS, et al. Automatic determination of an anatomical coordinate system for a threedimensional model of the human patella. J Biomech 2013;46:2093-6.

[21] Zavatsky AB, Oppold PT, Price AJ. Simultaneous in vitro measurement of patellofemoral kinematics and forces. J Biomech Eng 2004;126:351-6.

[22] Li G, Papannagari R, Nha KW, Defrate LE, Gill TJ, Rubash HE. The coupled motion of the femur and patella during in vivo weightbearing knee flexion. $\mathrm{J}$ Biomech Eng 2007;129:937-43.

340 [23] Nha KW, Papannagari R, Gill TJ, Van de Velde SK, Freiberg AA, Rubash HE, Li G. In vivo patellar tracking: clinical motions and patellofemoral indices. J Orthop Res 2008;26:1067-74.

[24] Grelsamer RP, Proctor CS, Bazos AN. Evaluation of patellar shape in the sagittal plane a clinical analysis. Am J Sports Med 1994;22:61-6. 
[25] Harbaugh CM, Wilson NA, Sheehan FT. Correlating femoral shape with patellar kinematics in patients with patellofemoral pain. J Orthop Res 2010;28:865-72.

350 [26] Azmy C, Guérard S, Bonnet X, Gabrielli F, Skalli W. EOS Orthopaedic imaging system to study patellofemoral kinematics: assessment of uncertainty. Orthop Traumatol Surg Res 2010;96:28-36.

[27] Fellows RA, Hill NA, MacIntyre NJ, Harrison MM, Ellis RE, Wilson DR. Repeatability of a novel technique for in vivo measurement of three-dimensional patellar tracking using magnetic resonance imaging. J Magn Reson Imaging 2005;22:145-53.

[28] Morton NA, Maletsky LP, Pal S, Laz PJ. Effect of variability in anatomical landmark location on knee kinematic description. J Orthop Res 2007;25:1221-30.

[29] Katchburian MV, Bull AMJ, Shih Y-F, Heatley FW, Amis AA. Measurement of patellar tracking: assessment and analysis of the literature. Clin Orthop Relat Res 2003;(412):241-59.

[30] Lafortune MA. The use of intra-cortical pins to measure the motion of the knee joint during walking [dissertation]. University Park (PA): The Pennsylvania State University; 1984.

370 [31] Grood ES, Suntay WJ. A joint coordinate system for the clinical description of three-dimensional motions: application to the knee. J Biomech Eng 1983;105:13644.

[32] Koskinen SK, Taimela S, Nelimarkka O, Komu M, Kujala UM. Magnetic resonance imaging of patellofemoral relationships. Skeletal Radiol 1993;22:403-10.

[33] Lee PP, Chalian M, Carrino JA, Eng J, Chhabra A. Multimodality correlations of patellar height measurement on x-ray, CT, and MRI. Skeletal Radiol 2012;41:130914.

[34] Nicolaas L, Tiqchelaar S, Koëter S. Patellofemoral evaluation with magnetic resonance imaging in 51 knees of asymptomatic subjects. Knee Surg Sports Traumatol Arthrosc 2011;19:1735-9.

385 [35] Bey MJ, Kline SK, Tashman S, Zauel R. Accuracy of biplane x-ray imaging combined with model-based tracking for measuring in-vivo patellofemoral joint motion. J Orthop Surg Res 2008;3:38.

[36] Fregly BJ, Rahman HA, Banks SA. Theoretical accuracy of model-based shape matching for measuring natural knee kinematics with single-plane fluoroscopy. J Biomech Eng 2005;127:692-9. 
[37] Hinterwimmer S, von Eisenhart-Rothe R, Siebert M, Welsch F, Vogl T, Graichen H. Patella kinematics and patello-femoral contact areas in patients with genu varum and mild osteoarthritis. Clin Biomech 2004;19:704-10.

[38] Li G, Papannagari R, Nha KW, DeFrate LE, Gill TJ, Rubash HE. The coupled motion of the femur and patella during in vivo weightbearing knee flexion. $\mathrm{J}$ Biomech Eng 2007;129:937-43.

400

[39] Patel VV, Hall K, Ries M, Lindsey C, Ozhinsky E, Lu Y, et al. Magnetic resonance imaging of patellofemoral kinematics with weight-bearing. J Bone Joint Surg Am 2003;85:2419-24.

405 [40] Shibanuma N, Sheehan FT, Stanhope SJ. Limb positioning is critical for defining patellofemoral alignment and femoral shape. Clin Orthop Relat Res 2005;(434):198206.

[41] Wu G, Siegler S, Allard P, Kirtley C, Leardini A, Rosenbaum D, et al. ISB recommendation on definitions of joint coordinate system of various joints for the reporting of human joint motion--part I: ankle, hip, and spine. International Society of Biomechanics. J Biomech 2002;35:543-8.

[42] McWalter EJ, Hunter DJ, Wilson DR. The effect of load magnitude on threedimensional patellar kinematics in vivo. J Biomech 2010;43:1890-7.

[43] Kedgley AE, Dunning CE. An alternative definition of the scapular coordinate system for use with RSA. J Biomech 2010;43:1527-31.

420 [44] Cole GK, Nigg BM, Ronsky JL, Yeadon MR. Application of the joint coordinate system to the three-dimensional joint attitude and movement representation: a standardization proposal. J Biomech Eng 1993;115:344-9. 


\section{List of Figures}
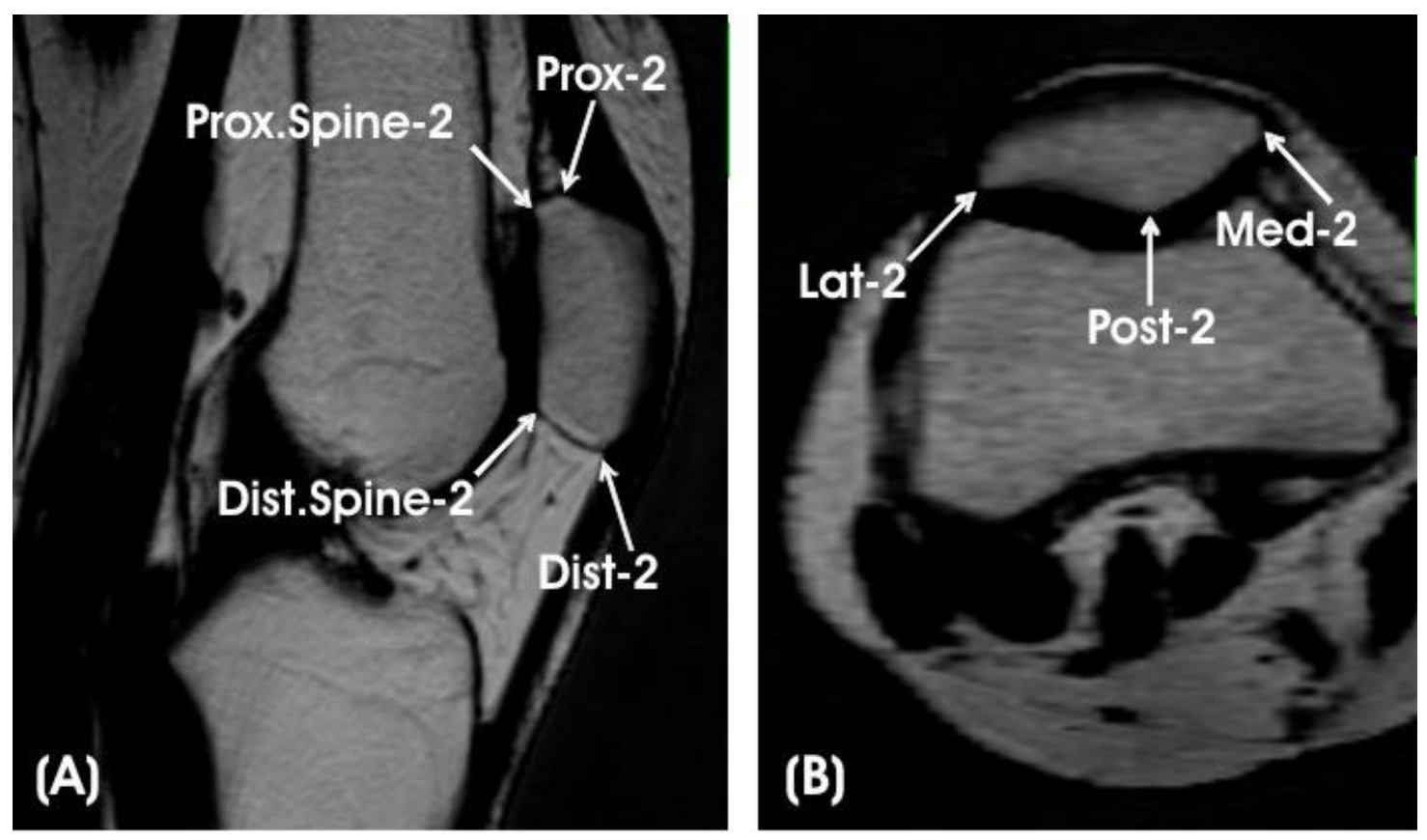

430 Fig. 1. Anatomical landmarks that were digitized on the patella (see also Table 2). The (A) sagittal mid-slice was found by calculating the slice that lay midway between the most medial and most lateral slices in the sagittal plane in which the patella was visible. The (B) axial mid-slice was found by calculating the slice that lay midway between the most proximal and most distal slices in the axial plane in which the patella was visible. 

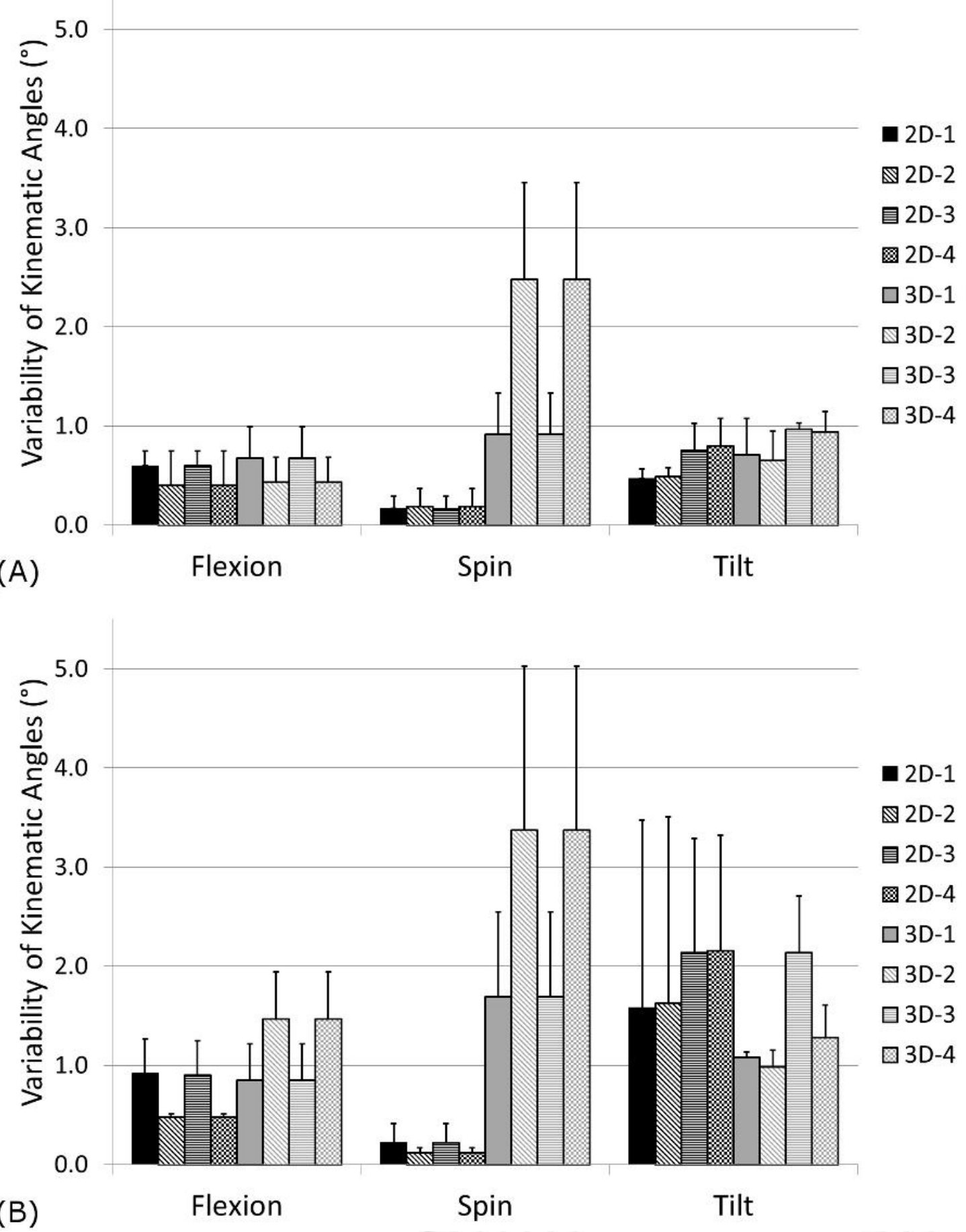

Fig. 2. (A) Intra- and (B) inter-investigator repeatability. Mean ( \pm 1 SD) repeatability for five trials, across all subjects, for eight different patellar coordinate systems (Table 3) 440 paired with a single femoral coordinate system. 


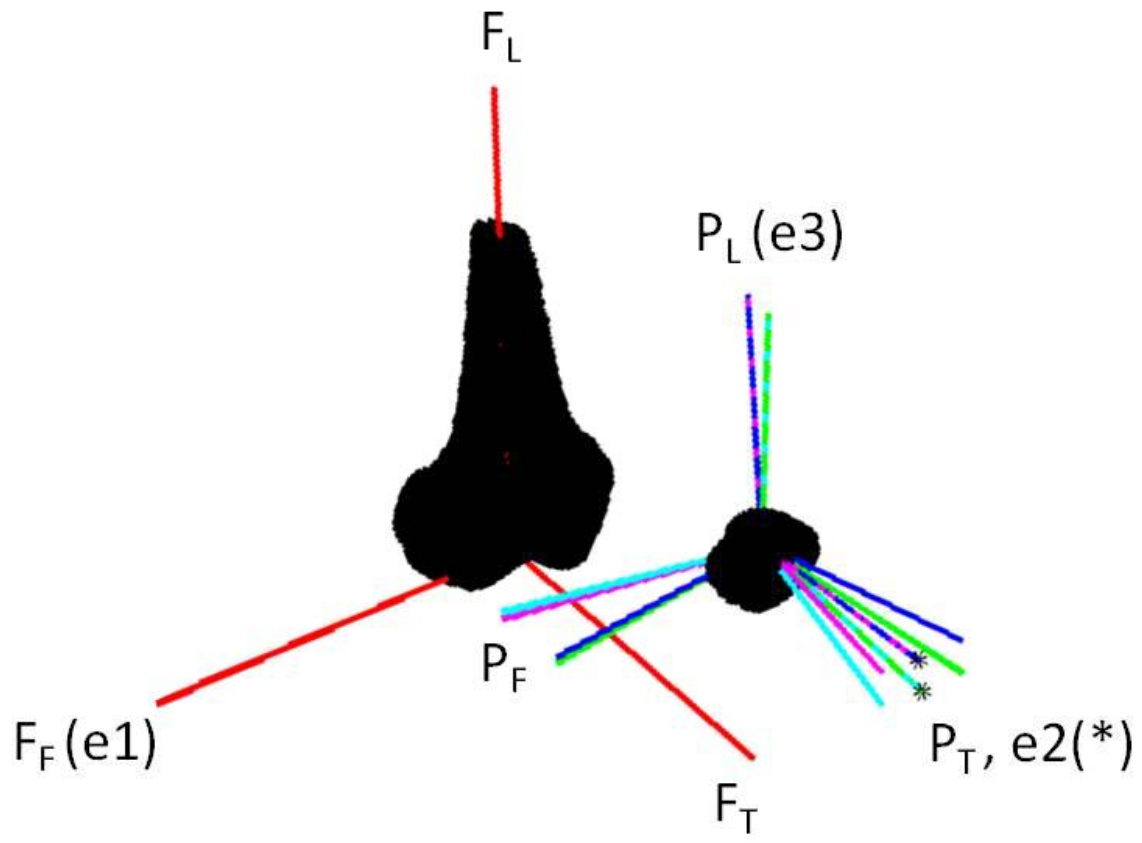

Fig. 3. Representative sample of the femoral coordinate system, and four patellar coordinate systems created with two-dimensional point digitization. F and $\mathrm{P}$ indicate the patellar coordinate system; subscripts F, L and T represent the flexion, long and third 445 axes. The modified Joint Coordinate System axes are e1, e2 (indicated by asterisk) and e3. Patellar coordinate systems 2D 1 through 4 are shown in magenta, cyan, blue and green, respectively. The patellar long axes are coincidental for coordinate systems 1 and 3 , and 2 and 4 (as indicated by the dashed line); as a result the floating axes of these pairs of coordinate systems are also coincidental (as indicated by the dashed line with the asterisk). 


\section{List of Tables}

455 Table 1. Landmarks used in the literature to create anatomical coordinate systems on the patella and femur.

\begin{tabular}{|c|c|c|}
\hline & Femur & Patella \\
\hline $\begin{array}{c}\text { Flexion } \\
\text { Axis }\end{array}$ & $\begin{array}{l}\text { Line joining medial and lateral epicondyles } \\
\text { [2-6] } \\
\text { Line joining medial and lateral posterior } \\
\text { points of condyles [7-9] } \\
\text { Line joining centres of spheres fit to femoral } \\
\text { condyles [10,11] } \\
\text { Plane touching posterior condyles [12] } \\
\text { Parallel to tibial coordinate system at full } \\
\text { extension [13] }\end{array}$ & $\begin{array}{l}\text { Line joining posterior point and lateral point } \\
{[9,18]} \\
\text { Line joining medial and lateral points }[8,11] \\
\text { Parallel to femoral axis at full extension }[3] \\
\text { Parallel to femoral axis at } 90^{\circ}[12] \\
\text { Parallel to tibial coordinate system at full } \\
\text { extension [13] }\end{array}$ \\
\hline $\begin{array}{l}\text { Long } \\
\text { Axis }\end{array}$ & $\begin{array}{l}\text { Anatomical (between two points along } \\
\text { femoral shaft) [1] } \\
\text { Anatomical (origin along centre of femoral } \\
\text { shaft) }[4,6,7,10,11] \\
\text { Mechanical (origin to centre of femoral } \\
\text { head) }[2,3] \\
\text { Trochlear (line along deepest portion of } \\
\text { trochlear groove) [12] } \\
\text { Parallel to tibial coordinate system at full } \\
\text { extension [13] }\end{array}$ & $\begin{array}{l}\text { Line joining proximal and distal points } \\
{[7,8,18]} \\
\text { Posterior flat edge }[19,20] \\
\text { Perpendicular to flexion and third [11] } \\
\text { Parallel to femoral axis at full extension [3] } \\
\text { Parallel to femoral axis at } 90^{\circ}[12] \\
\text { Parallel to tibial coordinate system at full } \\
\text { extension [13] } \\
\text { Between origin and distal point [2] } \\
\text { Line connecting insertions of quadriceps and } \\
\text { patellar tendons [10] }\end{array}$ \\
\hline $\begin{array}{c}\text { Third } \\
\text { Axis }\end{array}$ & $\begin{array}{l}\text { Perpendicular to flexion/extension and long } \\
\text { axes }[2,3,10] \\
\text { Parallel to tibial coordinate system at full } \\
\text { extension [13] }\end{array}$ & $\begin{array}{l}\text { Perpendicular to flexion and long axes [10] } \\
\text { Cross product of medial lateral axis and } \\
\text { vector from inferior apex along anterior } \\
\text { surface [11] } \\
\text { Parallel to femoral axis at full extension [3] } \\
\text { Parallel to femoral axis at } 90^{\circ}[12] \\
\text { Parallel to tibial coordinate system at full } \\
\text { extension [11] } \\
\text { Perpendicular to plane containing medial, } \\
\text { lateral and distal points [2] }\end{array}$ \\
\hline Origin & $\begin{array}{l}\text { Deepest point of the trochlear groove where } \\
\text { it meets the intercondylar notch }[8,14] \\
\text { Most proximal point of the intercondylar } \\
\text { notch [15] } \\
\text { Most posterior point on the sulcus groove in } \\
\text { the axial plane [9] } \\
\text { Proximal point of intercondylar notch along } \\
\text { to anatomical axis [12] } \\
\text { Centre of the intercondylar notch [13] } \\
\text { Midpoint between medial and lateral } \\
\text { epicondyles }[3,16]\end{array}$ & $\begin{array}{l}\text { Posterior point on axial midslice }[8,9] \\
\text { Midpoint of line joining medial and lateral } \\
\text { points of patella }[2,11] \\
\text { Centre of the patella }[3,6,7,12,14,21] \\
\text { Centre of the patella using most proximal, } \\
\text { distal, medial and lateral points [7] } \\
\text { Centre of the patellar ridge [13] } \\
\text { Projection of centre of patella onto line } \\
\text { connecting insertions of quadriceps and } \\
\text { patellar tendons [10] } \\
\text { Geometric centre [16] }\end{array}$ \\
\hline
\end{tabular}




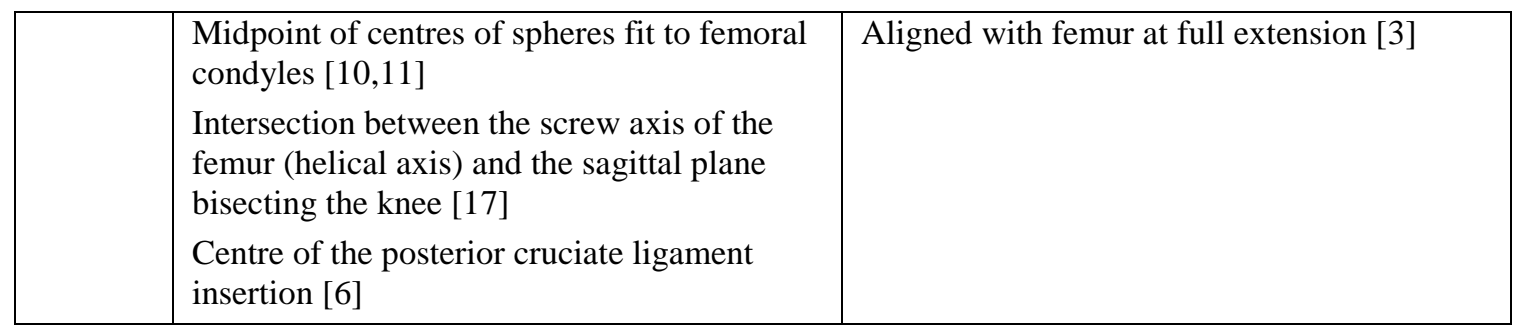

460 Table 2. Points that were digitized and calculated on the patella, listed with the intra-and inter-investigator repeatabilities of landmark selection.

\begin{tabular}{|c|c|c|c|}
\hline \multirow{3}{*}{ Description } & \multirow{3}{*}{ Abbreviation } & Intra-investigator & \multirow{2}{*}{\begin{tabular}{|c|} 
Inter-investigator \\
Mean \pm 1SD \\
\end{tabular}} \\
\hline & & Mean \pm 1SD & \\
\hline & & $(\mathrm{mm})$ & $(\mathrm{mm})$ \\
\hline $\begin{array}{l}\text { Most medial point selected on the axial } \\
\text { midslice }\end{array}$ & Med-2 & $0.17 \pm 0.12$ & $0.63 \pm 0.32$ \\
\hline $\begin{array}{l}\text { Most medial point selected in three } \\
\text { dimensions }\end{array}$ & Med-3 & $0.50 \pm 0.10$ & $0.91 \pm 0.08$ \\
\hline $\begin{array}{l}\text { Most lateral point selected on the axial } \\
\text { midslice }\end{array}$ & Lat-2 & $0.20 \pm 0.10$ & $0.76 \pm 0.43$ \\
\hline $\begin{array}{l}\text { Most lateral point selected in three } \\
\text { dimensions }\end{array}$ & Lat-3 & $0.43 \pm 0.02$ & $0.65 \pm 0.21$ \\
\hline $\begin{array}{l}\text { Most proximal point selected on the } \\
\text { sagittal midslice }\end{array}$ & Prox-2 & $0.37 \pm 0.07$ & $0.44 \pm 0.08$ \\
\hline $\begin{array}{l}\text { Most proximal point selected in three } \\
\text { dimensions }\end{array}$ & Prox-3 & $0.37 \pm 0.25$ & $0.84 \pm 0.27$ \\
\hline $\begin{array}{l}\text { Most distal point selected on the sagittal } \\
\text { midslice }\end{array}$ & Dist-2 & $0.11 \pm 0.02$ & $0.27 \pm 0.20$ \\
\hline $\begin{array}{l}\text { Most distal point selected in three } \\
\text { dimensions }\end{array}$ & Dist-3 & $0.34 \pm 0.04$ & $0.60 \pm 0.09$ \\
\hline $\begin{array}{l}\text { Most proximal point of patellar spine } \\
\text { selected on the sagittal midslice }\end{array}$ & Prox.Spine-2 & $0.30 \pm 0.21$ & $0.29 \pm 0.08$ \\
\hline $\begin{array}{l}\text { Most proximal point of patellar spine } \\
\text { selected in three dimensions }\end{array}$ & Prox.Spine-3 & $0.55 \pm 0.06$ & $0.97 \pm 0.39$ \\
\hline $\begin{array}{l}\text { Most distal point of patellar spine } \\
\text { selected on the sagittal midslice }\end{array}$ & Dist.Spine-2 & $0.21 \pm 0.19$ & $0.28 \pm 0.18$ \\
\hline $\begin{array}{l}\text { Most distal point of patellar spine } \\
\text { selected in three dimensions }\end{array}$ & Dist.Spine-3 & $0.52 \pm 0.42$ & $0.79 \pm 0.30$ \\
\hline $\begin{array}{l}\text { Most posterior point selected on the axial } \\
\text { midslice }\end{array}$ & Post-2 & $0.33 \pm 0.05$ & $0.46 \pm 0.11$ \\
\hline $\begin{array}{l}\text { Most posterior point selected in three } \\
\text { dimensions }\end{array}$ & Post-3 & $0.70 \pm 0.88$ & $1.67 \pm 0.85$ \\
\hline Midpoint of Med-2 and Lat-2 & Med.Lat-2 & $0.20 \pm 0.06$ & $0.49 \pm 0.08$ \\
\hline Midpoint of Med-3 and Lat-3 & Med.Lat-3 & $0.34 \pm 0.09$ & $0.63 \pm 0.24$ \\
\hline Midpoint of Prox-2 and Dist-2 & Prox.Dist-2 & $0.25 \pm 0.11$ & $0.29 \pm 0.08$ \\
\hline Midpoint of Prox-3 and Dist-3 & Prox.Dist-3 & $0.35 \pm 0.13$ & $0.53 \pm 0.18$ \\
\hline $\begin{array}{l}\text { Centre of Med-2, Lat-2, Prox-2, and Dist- } \\
2\end{array}$ & Centre-2 & $0.17 \pm 0.07$ & $0.32 \pm 0.03$ \\
\hline $\begin{array}{l}\text { Centre of Med-3, Lat-3, Prox-3, and Dist- } \\
3\end{array}$ & Centre-3 & $0.24 \pm 0.07$ & $0.44 \pm 0.15$ \\
\hline
\end{tabular}


465 Table 3. Landmarks used in the creation of the initial flexion and long axes for the four patellar coordinate system definitions.

\begin{tabular}{|c|c|c|}
\hline Name & Flexion axis & Long axis \\
\hline 2D-1 & Med-2 and Lat-2 & Prox-2 and Dist-2 [11,18] \\
\hline 2D-2 & Med-2 and Lat-2 & Prox.Spine-2 and Dist.Spine-2 \\
\hline 2D-3 & Post-2 and Lat-2 & Prox-2 and Dist-2 [11,18] \\
\hline 2D-4 & Post-2 and Lat-2 & Prox.Spine-2 and Dist.Spine-2 \\
\hline 3D-1 & Med-3 and Lat-3 [8,11] & Prox-3 and Dist-3 [7,8] \\
\hline 3D-2 & Med-3 and Lat-3 [8,11] & Prox.Spine-3 and Dist.Spine-3 \\
\hline 3D-3 & Post-3 and Lat-3 [9,18] & Prox-3 and Dist-3 [7,8] \\
\hline 3D-4 & Post-3 and Lat-3 [9,18] & Prox.Spine-3 and Dist.Spine-3 \\
\hline
\end{tabular}

Table 4. Mean ( \pm 1 SD) absolute differences in the resultant kinematic angles between 470 the eight patellar coordinate systems (listed in Table 3) for all subjects across six knee flexion angles. Comparisons are shown within the two-dimensional approaches, within the three-dimensional approaches, and between the two- and three-dimensional approaches that used the same landmarks for coordinate system creation. Significant differences $(\mathrm{p}<0.05)$ are indicated by a star $(*)$.

\begin{tabular}{|l|c|c|c|c|c|c|c|}
\hline $\begin{array}{l}\text { Flexion } \\
\left({ }^{\circ}\right)\end{array}$ & $2 \mathrm{D}-1$ & $2 \mathrm{D}-2$ & $2 \mathrm{D}-3$ & $2 \mathrm{D}-4$ & $3 \mathrm{D}-1$ & $3 \mathrm{D}-2$ & $3 \mathrm{D}-3$ \\
\hline 2D-2 & $10.8 \pm 3.5^{*}$ & & & & & & \\
\hline 2D-3 & $0.0 \pm 0.0$ & $10.8 \pm 3.5^{*}$ & & & & & \\
\hline $2 \mathrm{D}-4$ & $10.8 \pm 3.5^{*}$ & $0.0 \pm 0.0$ & $10.8 \pm 3.5^{*}$ & & & & \\
\hline $3 \mathrm{D}-1$ & $1.0 \pm 1.2^{*}$ & & & & & & \\
\hline 3D-2 & & $1.4 \pm 1.5$ & & & $11.5 \pm 3.0^{*}$ & & \\
\hline 3D-3 & & & $1.0 \pm 1.2^{*}$ & & $0.0 \pm 0.0$ & $11.5 \pm 3.0^{*}$ & \\
\hline $3 \mathrm{D}-4$ & & & & $1.4 \pm 1.5$ & $11.5 \pm 3.0^{*}$ & $0.0 \pm 0.0$ & $11.5 \pm 3.0^{*}$ \\
\hline
\end{tabular}

\begin{tabular}{|l|c|c|c|c|c|c|c|}
\hline Spin $\left(^{\circ}\right)$ & $2 \mathrm{D}-1$ & $2 \mathrm{D}-2$ & $2 \mathrm{D}-3$ & $2 \mathrm{D}-4$ & $3 \mathrm{D}-1$ & $3 \mathrm{D}-2$ & $3 \mathrm{D}-3$ \\
\hline $2 \mathrm{D}-2$ & $1.5 \pm 1.5$ & & & & & & \\
\hline $2 \mathrm{D}-3$ & $0.0 \pm 0.0$ & $1.5 \pm 1.5$ & & & & & \\
\hline $2 \mathrm{D}-4$ & $1.5 \pm 1.5$ & $0.0 \pm 0.0$ & $1.5 \pm 1.5$ & & & & \\
\hline 3D-1 & $3.4 \pm 2.3$ & & & & & & \\
\hline $3 \mathrm{D}-2$ & & $3.5 \pm 3.1$ & & & $5.0 \pm 3.8$ & & \\
\hline 3D-3 & & & $3.4 \pm 2.3$ & & $0.0 \pm 0.0$ & $5.0 \pm 3.8$ & \\
\hline 3D-4 & & & & $3.5 \pm 3.1$ & $5.0 \pm 3.8$ & $0.0 \pm 0.0$ & $5.0 \pm 3.8$ \\
\hline
\end{tabular}

\begin{tabular}{|l|c|c|c|c|c|c|c|}
\hline Tilt $\left(^{\circ}\right)$ & $2 \mathrm{D}-1$ & $2 \mathrm{D}-2$ & $2 \mathrm{D}-3$ & $2 \mathrm{D}-4$ & $3 \mathrm{D}-1$ & $3 \mathrm{D}-2$ & $3 \mathrm{D}-3$ \\
\hline 2D-2 & $1.0 \pm 0.8^{*}$ & & & & & & \\
\hline 2D-3 & $21.1 \pm 2.4^{*}$ & $22.1 \pm 2.6^{*}$ & & & & & \\
\hline $2 \mathrm{D}-4$ & $20.3 \pm 2.5^{*}$ & $21.2 \pm 2.4^{*}$ & $0.9 \pm 0.7^{*}$ & & & & \\
\hline $3 \mathrm{D}-1$ & $2.5 \pm 1.4^{*}$ & & & & & & \\
\hline $3 \mathrm{D}-2$ & & $1.9 \pm 1.1$ & & & $1.8 \pm 1.6^{*}$ & & \\
\hline $3 \mathrm{D}-3$ & & & $5.7 \pm 4.8^{*}$ & & $25.5 \pm 5.8^{*}$ & $27.3 \pm 6.2^{*}$ & \\
\hline $3 \mathrm{D}-4$ & & & & $3.3 \pm 2.6^{*}$ & $22.2 \pm 2.4^{*}$ & $24.0 \pm 2.9^{*}$ & $4.7 \pm 1.5^{*}$ \\
\hline
\end{tabular}

